\title{
Extended adipofascial wrap around radial forearm flap for hard palate reconstruction
}

\author{
Ashok B. C., Pradeep Kumar Nagaraj, Srikanth Vasudevan, \\ Anantheshwar Y. N. Rao, Sudarshan Reddy Nagireddy, Ritu Singh Batth \\ Department of Plastic and Cosmetic Surgery, Manipal Hospital, Bengaluru, Karnataka, India
}

Address for correspondence: Dr. Pradeep Kumar Nagaraj, Department of Plastic Surgery, Manipal Hospital, Bengaluru - 560017 , Karnataka, India. E-mail: stalinpradeep@gmail.com

\section{ABSTRACT}

Background: While using radial forearm free flap in palate reconstruction, the pedicle lies in the nasal floor, constantly exposed to the nasal secretions and turbulent air current. To overcome this problem, we have designed a procedure which utilises the adipofascial extension to wrap the pedicle and nasal side of the flap. Materials and Methods: The study was done during 2017 and 2018, 2 years' period. Totally 13 consecutive patients with defect in the palate status post-oncological resection and those in whom local flaps were not enough to cover the defect were included into the study. These patients were divided into two groups. First group in whom adipofascial extension was not used to cover the pedicle and second group in whom adipofascial extension was used to cover the pedicle. The incidence of nasal crusting, secondary haemorrage, blow out and flap necrosis were analysed and compared. Results: In Group 1, we had 2 among 6 (33\%) patients with secondary haemorrage. One patient had partial flap loss. On exploring, we noticed thrombosis of cephalic vein. We did not had any incidence of blow out of the pedicle. In Group 2, none of the patients had any secondary haemorrage. All flaps healed well. On doing nasal endoscopy at 6 months of follow-up, all flaps showed complete mucosalisation at the nasal side. Conclusion: Use of adipofascial extension while planning a radial forearm free flap to cover the nasal side of the flap and pedicle in the nasal floor helps to reduce the nasal crusting and secondary haemorrhage.

\section{KEY WORDS}

Adipofascial extension; hard palate reconstruction; mucosalisation; radial forearm free flap

\section{INTRODUCTION}

adial forearm free flap is the workhorse flap in oral cavity and palate reconstruction..$^{[1]}$ While using Radial forearm flap in palate reconstruction,

\begin{tabular}{|l|l|}
\hline \multicolumn{2}{|c|}{ Access this article online } \\
\hline Quick Response Code: & Website: \\
\hline & www.ijps.org \\
\hline
\end{tabular}

the pedicle lies in the nasal floor, constantly exposed to the nasal secretions and turbulent air current. This kind of nasal environment leads to drying, crusting and

This is an open access journal, and articles are distributed under the terms of the Creative Commons Attribution-NonCommercial-ShareAlike 4.0 License, which allows others to remix, tweak, and build upon the work non-commercially, as long as appropriate credit is given and the new creations are licensed under the identical terms.

For reprints contact: reprints@medknow.com

How to cite this article: Ashok BC, Nagaraj PK, Vasudevan S, Rao AY, Nagireddy SR, Batth RS. Extended adipofascial wrap around radial forearm flap for hard palate reconstruction. Indian $\mathrm{J}$ Plast Surg 2018;51:306-8. 
desiccation of the pedicle which has a potential risk of vascular compromise (thrombosis or blowout).

To overcome this problem, we have designed a procedure which utilises the adipofascial extension to wrap the pedicle on nasal side of the flap.

\section{MATERIALS AND METHODS}

The study was conducted for a period of 2 years between 2017 and 2018. A Total of 13 patients were included in the study with defect in the palate following oncological resection and those in whom local flaps were not enough to cover the defect [Figure 1, showing the hard palate defect]. These patients were divided into two groups. First group, six patients who were followed retrospectively and in whom adipofascial extension was not used to cover the pedicle and second group, seven patients in whom adipofascial extension was used to cover the pedicle [Figures 2 and 3a, b]. In Group 1, patients' data was collected by inpatient and outpatient records. In Group 2, Post-operatively, patients were followed up for 5-7 days in the hospital and then at 2 weeks, 3 months and 6 months. Any evidence of secondary haemorrage from the pedicle, thrombosis of the vessels in the nasal floor and flap loss due to vascular issues apart from that due to anastomotic problems were charted and compared between two groups.

\section{RESULTS}

In Group 1, we had 2 among 6 (33\%) patients with secondary haemorrage. All of them presented with trying to remove the crusting from the nose which lead to bleeding. One patient had partial flap loss. On surgical exploration, we noticed thrombosis of cephalic vein. We did not have any incidence of blow out of the pedicle.

In Group 2, none of the patients had secondary haemorrage, all flaps healed well. On doing nasal endoscopy at 6 months, all flaps showed complete mucosalisation at the nasal side [Figure $4 a$ and $b$ ].

\section{DISCUSSION}

The Chinese flap described by Yang et al. (1981) has been very handy and good match for hard palate especially when bony replacement is not required. ${ }^{[1]}$ It is a thin pliable flap with a very good pedicle length.

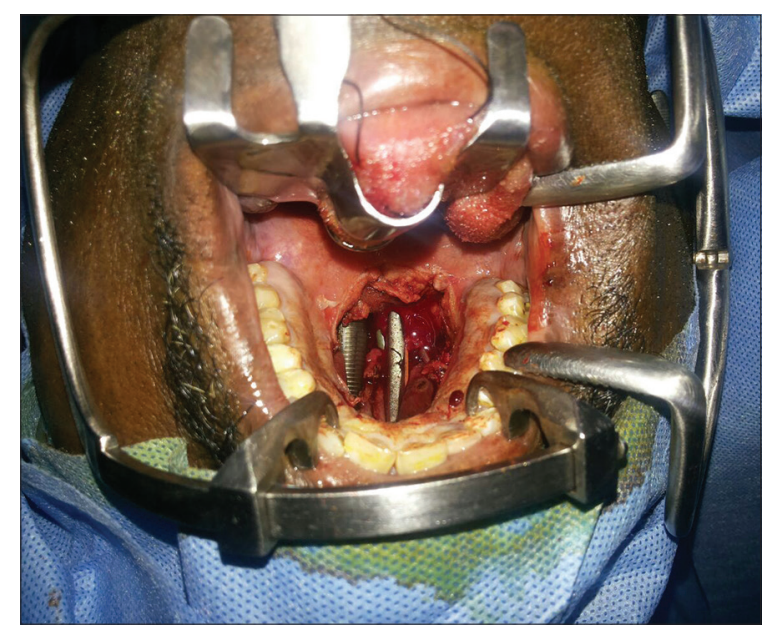

Figure 1: Hard palate defect intra-operatively - showing the communication of oral and nasal cavity

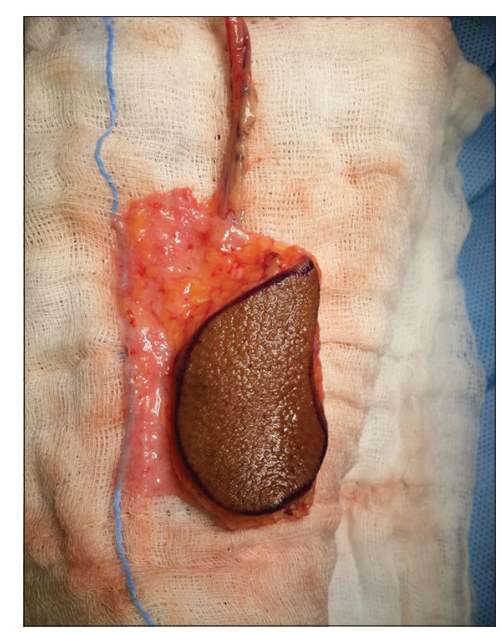

Figure 2: Radial fore arm flap harvested - dorsal cutaneous surface

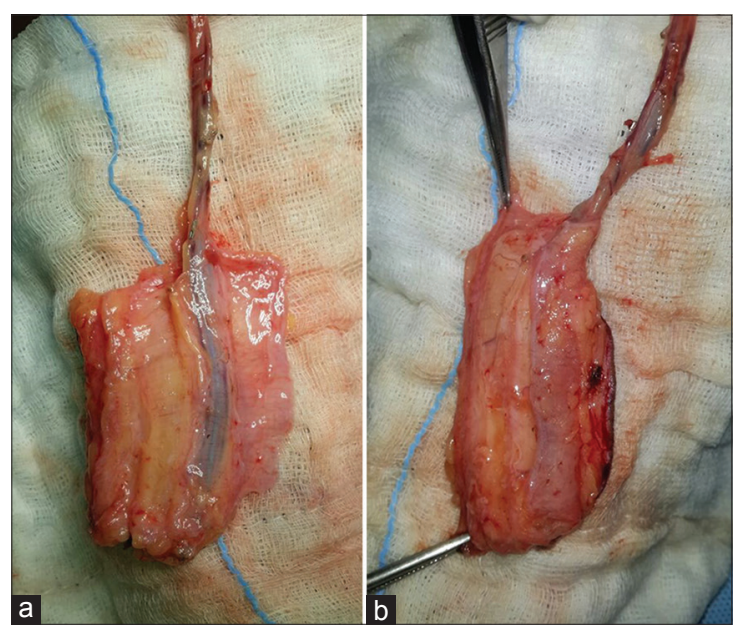

Figure 3: (a) Ventral side of the radial forearm flap without the adipofascial cover. (b) Ventral side of the radial forearm flap with the adipofascial cover - note that the pedicle is completely protected

During palate reconstruction, both nasal and oral surface need to be closed so that healing is good. Although 


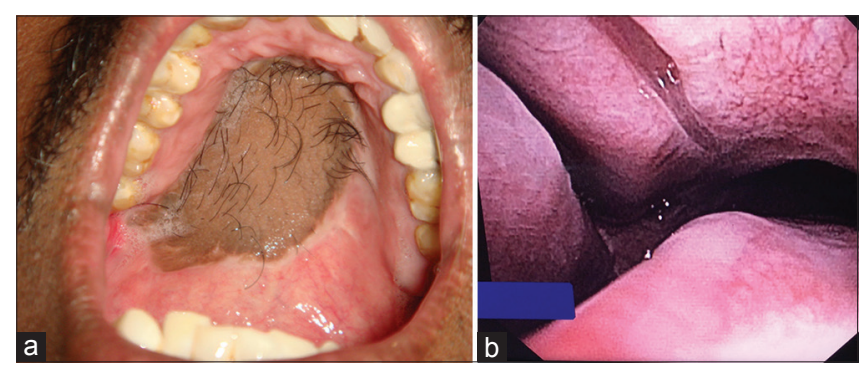

Figure 4: (a) Post-operative result - oral side of the flap. (b) Naso endoscopy done at 6 months shows complete mucosalisation of the nasal surface of the flap

reconstruction with double-paddled radial artery free flap or two different flaps so that both nasal and oral lining is epithelium is an option, but this made the flap bulky causing speech problems and halitosis..$^{[2]}$ In addition, there is a mention in the literature ${ }^{[3,4]}$ regarding prelaminated radial forearm flaps with mucosal tissue (either autologous or tissue engineered) to line nasal floor; however, these are staged procedures and difficult in an oncological setting. During the refinement process, single-paddled radial forearm flap to line the oral cavity was used and nasal surface was kept raw. This improved speech, halitosis was decreased. The nasal side raw area was thought to mucosalise and to contract over time. The complete mucosalisation of nasal raw area in an oncological setting would take around 11-12 months. ${ }^{[4,5]}$ During this time, the pedicle is constantly exposed to nasal secretions and crusting. In our first group of six consecutive cases where single paddle radial forearm flap without facial extensions was used, we had two patients who came back with complaints of secondary haemorrhage, bleeding from the nose during 3-6 weeks of post-operative. Bleeding was managed conservatively with saline drops none required exposure and cauterising the bleeding vessels One patient had partial flap loss on exploration, we noticed thrombosis of cephalic vein. We did not have any incidence of blow out. In the review of literature, we could not find articles quoting this particular problem.

Looking back into the issue, only precaution to prevent crusting of the vessels was use of saline nasal sprays, ${ }^{[4]}$ but even with the saline nasal sprays the risk of crusting remained the same. Although there is not much of evidence in literature on pedicle-related complications due to drying and crusting, the fear of this potential hazard always lies in the back of the mind of every microvascular surgeon. ${ }^{[2]}$
Adipofascial extended forearm flaps have been used in oral cavity reconstruction to fill the dead space and achieve quick healing. ${ }^{[6]}$ We have adopted the same principle such that Adipofascial extension would cover the pedicle in the nasal floor on the nasal side of the flap preventing direct exposure to the turbulent air current. We have used this technique in seven consequent hard palate defects. Followed them for 6 months, nasal endoscopy was done at the end of 6 months to see the mucosalisation pattern. It was very evident that the problems of nasal crusting and secondary haemorrhage were not encountered in these individuals and the nasal endoscopy at the end of 6 months showed complete mucosalisation of the flap. We have not studied regarding the contraction of the flap on the nasal side.

\section{CONCLUSION}

Use of adipofascial extension while planning a radial forearm free flap to cover the nasal side of the flap and pedicle in the nasal floor helps to reduce the nasal crusting and secondary haemorrhage. Being simple and single staged, it is one of the options for solving the problem of nasal bleeding. It also hastens mucosalisation of the nasal side of the flap since adipofascial layer acts as additional vascularised layer.

\section{Financial support and sponsorship \\ Nil.}

\section{Conflicts of interest}

There are no conflicts of interest.

\section{REFERENCES}

1. Duflo S, Lief F, Paris J, Giovanni A, Thibeault S, Zanaret M. Microvascular radial forearm fasciocutaneous free flap in hard palate reconstruction. Eur J Surg Oncol 2005;31:784-91.

2. Lorenzo A. Principles, techniques and applications in microsurgery. Ann Plastic Surg 2009;62:600.

3. Millesi W, Rath T, Millesi-Schobel G, Glaser C. Reconstruction of the floor of the mouth with a fascial radial forearm flap, prelaminated with autologous mucosa. Int J Oral Maxillofac Surg 1998;27:106-10.

4. Lauer G, Schimming R, Gellrich NC, Schmelzeisen R. Prelaminating the fascial radial forearm flap by using tissue-engineered mucosa: Improvement of donor and recipient sites. Plast Reconstr Surg 2001;108:1564-72.

5. Shibahara T, Noma H, Takeda E, Hashimoto S. Morphologic changes in forearm flaps of the oral cavity. J Oral Maxillofac Surg 2000;58:495-9.

6. Jeng SF, KuoYR, Wei FC, An PC, Su CY, Chien CY, etal. Free radial forearm flap with adipofascial tissue extension for reconstruction of oral cancer defect. Ann Plast Surg 2002;49:151-5. 